\title{
Sex Determination in Nutmeg Seedlings Using Scar Primers
}

\section{Francis Dadzie Mintah}

\author{
Kwame Nkrumah' University of Science and Technology, Ghana \\ kofimintahfm@yahoo.com
}

Keywords: Nutmeg, SCAR primers, sex determination

\begin{abstract}
Myristica fragrans $\mathrm{H}$. is a dioecious plant with male and female flowers on different trees. At the juvenile stage of nutmeg, their sexes is not morphologically identified until at the flowering stage. However, the female is more economical than the male plants. This challenge is making the work of nutmeg farmers difficult and also inhibiting the development of the spice and flavouring industry in Ghana. Hence, the use of molecular technique to characterize male and female nutmeg plants. SCAR markers are easy, specific, and reliable and have a high sense of reproducibility than other markers. Two different primers (F-Napf-76, R-Napf-77 and F-Napf-70, R-Napf-71) were used for the PCR amplification. It was revealed that the total genomic DNA of samples from both mature plant and seedlings of nutmeg were of good quality and was much concentrated by giving good DNA bands. Although there were no distinctions among the bands, they all lie at the same level $(0.3 \mathrm{kbp})$ indicating that the samples were of similar molecular weight. However, double PCR amplification was not seen in all samples when run on a 1\% agarose gel but single amplifications were observed.
\end{abstract}

\section{Introduction}

Myristica fragrans $\mathrm{H}$. is a dioecious plant with male and female flowers on different trees although hermaphrodite flowers and bisexual trees occur rarely. It produces two separate spices, namely nutmeg and mace. Nutmeg is the dried kernel of the seed and the mace is the dried aril surrounding the seed [1]. Nutmeg is indigineous to Mollucas Islands (Indonesia) and thrives well in warm humid conditions in locations with annual rainfall of $150 \mathrm{~cm}$ and more [1]. However, it is currently produced in many places such as India, Malaysia, various Caribbean islands, New Guinea, and Africa; to be specific Ghana which was introduced in the 1960's by the Moluccas. The nutmeg plant is noted to be propagated by two different methods: seedling and vegetative. Gestation period is more than a month and it takes approximately twenty (20) years to bear mature fruits then after that it bears fruit every year and production rate increases after ten years. World production of nutmeg is estimated to an average between 10,000 and 12,000 tonnes $(9,800$ and 12,000 long tons; 11,000 and 13,000 short tons) per year, with annual world demand estimated at 9,000 tonnes (8,900 long tons; 9,900 short tons); production of mace is estimated at 1,500 to 2,000 tonnes (1,500 to 2,000 long tons; 1,700 to 2,200 short tons) [2]. In Ghana, the Plant Genetic Resource Research Institute of the Council for Scientific and Industrial Research (Bunso) harvested about 96,136 nutmeg fruits in the year 2012 and about 15,017 nutmeg fruits in the year 2013.The economic importance of nutmeg is enormous. The fruit has proven to be very useful in the preparation of brain tonic, for skin care, as flavoring additive, for pain relief, liver and kidney detoxifier, sleep aid and for bad breath treatment [3]. Nutmeg is safe in lesser quantities but toxic in higher quantities [4]. Nutmeg causes a wide adverse reaction to the nervous system and gastrointestinal tissues. It also causes rapid heart rate and dehydration [5]. However, in its freshlyground form, nutmeg contains myristicin, a monoamine oxidase inhibitor and psychoactive substance which can induce convulsions, palpitations, nausea, eventual dehydration, and generalized body pain [6].

An important problem that farmers face in the production of nutmeg is that the sex determination of nutmeg is not revealed morphologically at the juvenile stage until the flowering stage, making it difficult to obtain an appropriate ratio of males and females plants to be planted on the field. Although there has been a lot of approach in determining the sexes of nutmeg at the 
seedling stage for example; leaf venation, genetic tester etc. but has still not been the best [1]. This problem is inhibiting the development of the spice and flavoring industry in Ghana. In order to solve such problem, molecular identification techniques using DNA marker is to be applied rather than a traditional discrimination method that is carried out with comparisons of morphological traits. Therefore, SCAR markers were used because they are easy, specific, and reliable and have a high sense of reproducibility than other markers. SCAR markers have been developed for sex determination in alien crops [7, 8]. Parasnis et al. [9] developed a male-specific SCAR marker in papaya by cloning a male-specific RAPD $(831 \mathrm{bp})$ fragment and designing longer primers. Lee et al. [10] discriminated among the genetic polymorphisms of the Korean ginseng cultivar, $P$. quinquefolius, and $P$. notoginseng through the use of SCAR markers. Manoj et al., [11] distinguished between the male and female Piper longum through the development of SCAR primers MPS1A and MPS1B. Vinod et al. [12] reported that OPO-08 RAPD marker amplified a $1263 \mathrm{bp}$ band in male which was absent in females of Pandanus fascicularis. A SCAR marker (MSSRF-01) was designed for this fragment and continued to amplify the specific allele in all the male plants. Southern hybridization results also confirmed the RAPD work and strongly suggested that (MSSRF-01) is male specific molecular marker in Pandanus fascicularis. Devaiah and Venkatasubramanian [13] developed a SCAR marker for authentication of Pureria tuberosa. OPA 08600 bp marker specific to P. tuberosa. This RAPD amplicon was converted to the SCAR marker which revealed the expected amplicon $(320 \mathrm{bp})$ in male plants. However, by increasing the specificity, the results are less sensitive to changes in reaction conditions and are more reproducible [14]. Consequently, in order to avoid wastage of labour, time and resources, assurance of yield outcome, prevent contamination from unintended species or trees confronting farmers the purpose of the study was to identify the sexes of nutmeg seedlings using SCAR markers, and facilitate better management of nurseries to obtain a higher proportion of females to males seedlings of nutmeg to be planted in the field.

\section{Literature Review}

\section{Sex determination}

In the animal kingdom, the separation of female and male functions among individuals is the common sexual system. In contrast, most flowering plants are hermaphroditic, with flowers bearing both female and male reproductive organs. Only about $6 \%$ of angiosperms are dioecious, where individuals either produce staminate or pistillate flowers [15]. In a minority of dioecious plants, sex determination depends on sex chromosomes, usually an XY system, in which males are heterogametic (XY) and females are homogametic [16-18]. According to Matsunaga and Kawano [18], two types of sex chromosomes exist in nature homomorphic sex chromosomes, in which the sex chromosomes are morphologically indistinguishable from autosomes, and heteromorphic sex chromosomes, which can be discriminated in cytological analyses. Undoubtedly, Heteromorphic sex chromosomes have been reported in several families (e.g., Cannabis and Humulus, Cannabinaceae; Silene, Caryo-phyllaceae) [18], but our understanding of their evolution and genetics is still relatively poor [19].

\section{Conventional Sex diagnostics}

Differences between clones and closely related species are not always absolute using morphological characters [20] and distinguishing between clonal and seedling progenies are impossible due to very limited morphological variations in this crop [21]. However, several attempts made for identification of sex of nutmeg seedlings based on morphological and chemical characters [21] reported only limited successes [22]. Phadnis and Choudhary [23] advocated a colorimetric test that they claimed could distinguish sex in approximately two thirds of seedlings while Nayar et al. [24] examining the epidermal cells of nutmeg leaf described the different structures of calcium oxalate crystals in seedlings of male and female plants. In a preliminary study, it was indicated that characteristics such as leaf shape, essential oil content and composition and 
profile of phenolics differ in male and female plants [25]. Contrarily, a study conducted by Mezencev et al. [26] confirmed the absence of obvious relationship between the extents of morphological variations and that of changes at the DNA level already reported in rice. Therefore, earlier studies suggested the use of similar molecular techniques for identification in case of a confusion or misidentification of genotypes where not much of a morphological variation whatsoever exist [27].

\section{Molecular sex diagnostics}

SCAR markers were developed for sex determination in alien crops $[7,8]$. However extensive studies involving sex pooled DNA samples from more number of individuals and primers are needed to confirm this. Therefore, for molecular markers linked to specific genes there is a need for screening large number of RAPD primers [28] which is usually more than 50bp [22]. A high potential of RAPD markers in detecting molecular polymorphism between individuals of an accession [29], phenotypically pure stocks [30] and intra varietal variations among donor plants [26] have been demonstrated. Interestingly, Lemos et al. [31] identified a sex specific primer marker in papaya and a PSDM was isolated. It is likely that these markers are linked to sex determining loci, though the sex determining mechanism is not yet characterized in nutmeg. Nevertheless, female specific bands were isolated by RAPD in Myristica [32]. Furthermore, Lee et al. [10] conducted a study to develop the easier discrimination method, which could demonstrate genetic polymorphisms among the Korean ginseng cultivar, $P$. quinquefolius, and $P$. notoginseng by using ISSR marker technique and conversion of polymorphic ISSR markers to SCAR markers.

\section{Materials and Methods}

\section{Source of plant materials}

Twenty (20) seedlings of nutmeg of six (6) months old together with leaves from known sex mature nutmeg plants were taken from a nutmeg plantation in Bunso which is located in the Eastern Region of Ghana.

\section{Reaction Mix Preparation and Concentrations}

The Accupower reaction mixture for PCR contained $8 \mu$ master mix (containing the premix, both male specific and gender neutral primers dissolved in distilled water), and $2 \mu$ l of extracted total genomic DNA, raising the working volume of the PCR reaction mix to $10 \mu 1$ for each tube.

\section{Gel preparation}

A 1\% agarose gel was used for running of both the genomic and the PCR samples as well. Agarose gel was used rather than polyacrylamide gel because of its ability to hold the DNA fragments within the gel without running into the electrolyte containing TAE buffer.

\section{DNA extraction and gel electrophoresis}

Extraction of total genomic of DNA of the leaf samples was done using the CTAB protocol developed by Takrama [33]. A 1\% agarose gel was used for running of both the genomic and the PCR samples as well. Portions of the extracted genomic DNA were loaded onto the agarose gel and subjected to electricity. The gel together with the electrolyte and the electricity works with the principle that small fragments of DNA run down the gel faster than larger ones. Gel electrophoresis of the total genomic DNA was done to check the quality or integrity of the DNA. DNA isolates were subjected to PCR and PCR products were loaded on the gel to check variation and polymorphism. 
Table 1. Sequence of Primers Used

\begin{tabular}{llll}
\hline PRIMER & DESIGNATION & SEQUENCE & SIZE (bp) \\
1 & F-Napf-76 & 5'-GAGGATCCCTATTAGTGTAAG-3' & 21 \\
& R-Napf-77 & 5'-GAGGATCCCTTTTGCACTCTG-3' & 21 \\
2 & F-Napf-70 & 5'GGATCCCTATTAG-3' & 15 \\
& R-Napf-71 & 5'-GAGGATCCCTTTTGC-3' & 15 \\
\hline
\end{tabular}

Source: Parasnis et al., [9]

Table 2. Optimized PCR parameters

$\left.\begin{array}{lll}\text { STEP } & \text { TEMPERATURE }\left({ }^{\mathbf{C}} \mathbf{C}\right) & \text { DURATION } \\ \text { Initial Denaturation } & 95 & 3 \text { minutes } \\ \text { Denaturation } & 95 & 1 \text { minutes } \\ \text { Annealing } & 55(\text { primer } 1) 45(\text { primer } 2) & 2 \text { minute } \\ \text { Extension } & 72 & 7 \text { minutes } \\ \text { Final Extension } & 72 & 5 \text { minutes }\end{array}\right] 40$ cycles

\section{Results}

\section{DNA Integrity test}

DNA quality check showed that good quality DNA was extracted from all leaf samples as shown in Fig. 1 below. It clearly shows that the total genomic DNA of samples from both mature plant and seedlings of nutmeg were of good quality and was much concentrated by giving good DNA bands. Although there were no distinctions among the bands, they all lie at the same level $(0.3 \mathrm{kbp})$ indicating that the samples were of similar molecular weight.

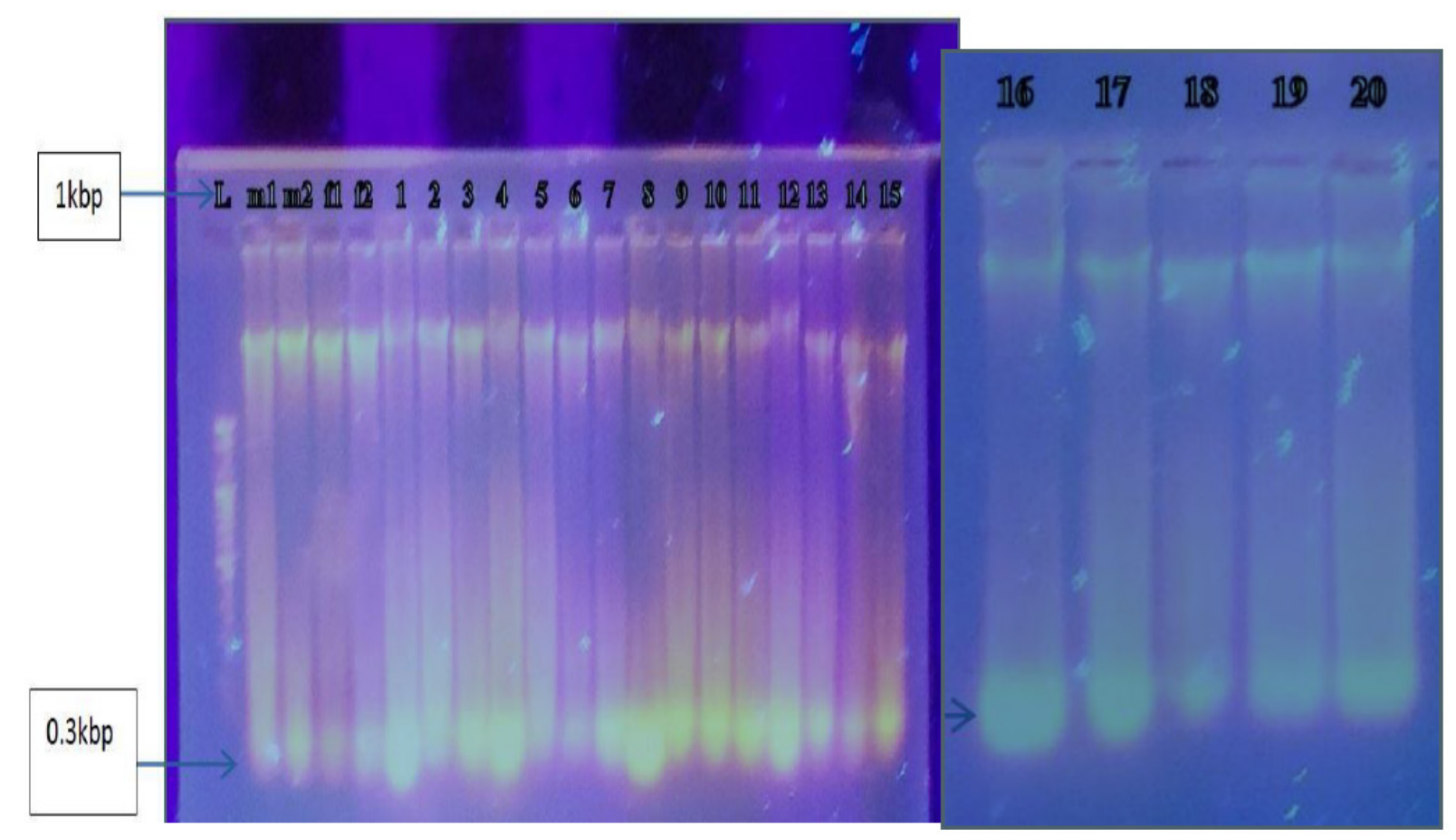

Figure 1. Extracted genomic DNA integrity test. Lane L 1kbp ladder, lane M1-F2 matured male and female, lane 1-20 contains seedlings

\section{PCR amplification}

DNA fragments appeared clearly after running the genomic DNA with the Accupower premix using the PCR cycling parameter. Fig. 2 below demonstrated that DNA fragments from the mature males are of the same kilo base pairs $(0.40 \mathrm{kbp})$ lying at the same level but those from the mature 
female are of different base pairs. However, Lanes 4, 5, and 6 contained DNA samples from an assumed male, assumed female, and assumed male respectively but lie at the same level corresponding to the mature male sample but do not correspond to the marker. Interestingly, there was single amplification for all samples.

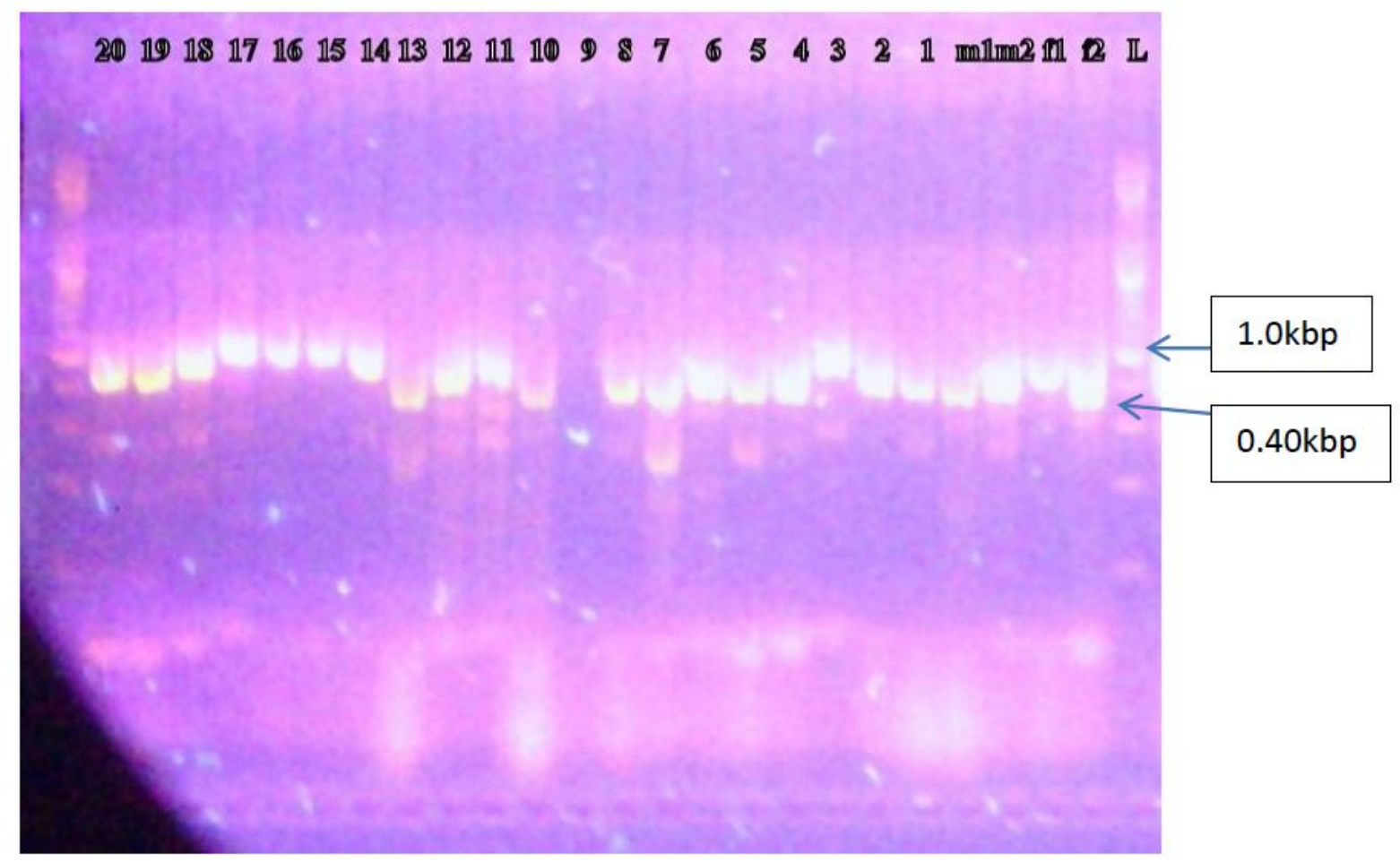

Figure 2. Separated PCR products of extracted genomic DNA on a $1 \%$ agarose gel (Primer 1). L is $1 \mathrm{kbp}$ marker, M1-F2 contained mature male and female respectively, lane 1-20 contained seedlings

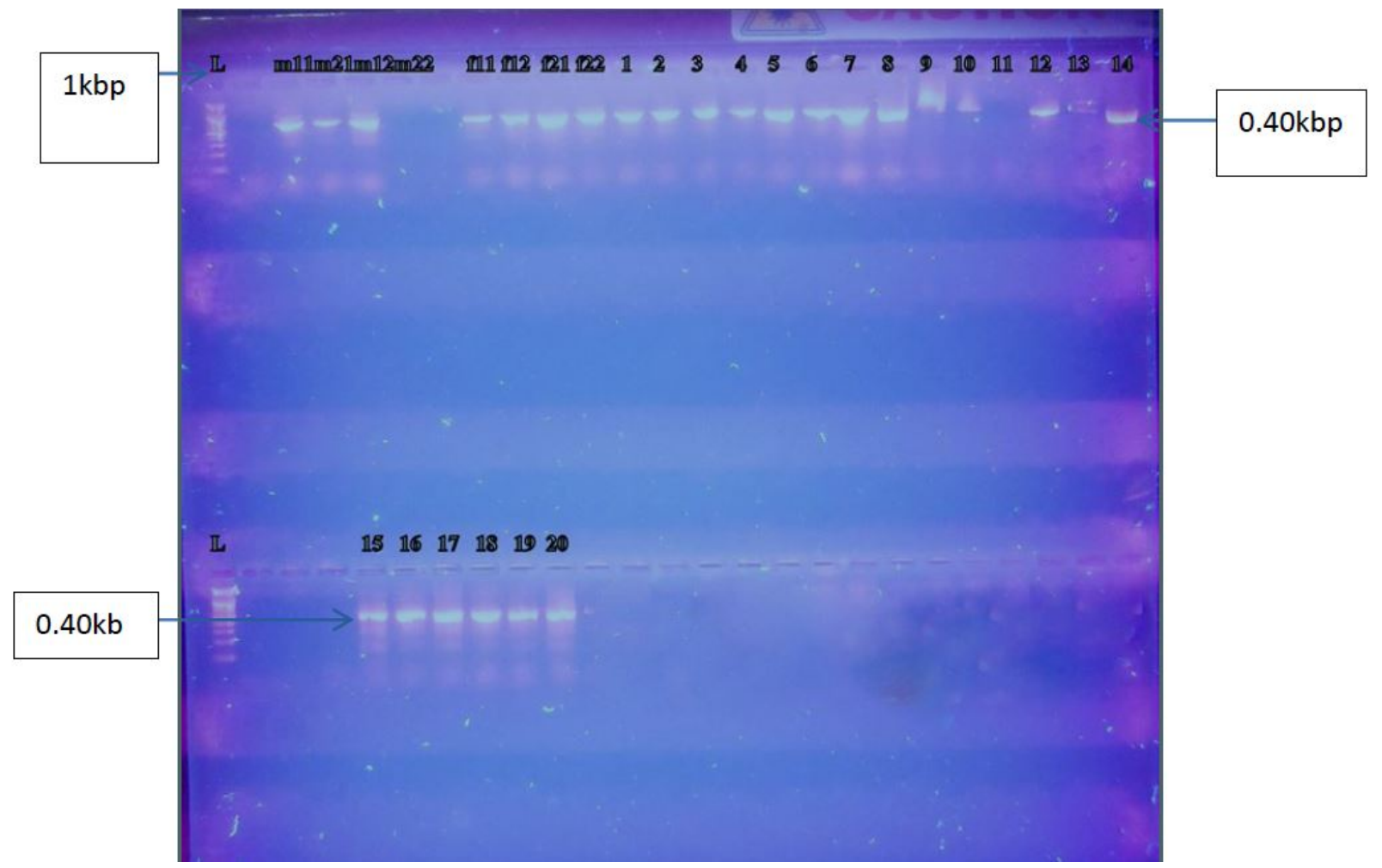

Figure 3. Separated PCR products of extracted genomic DNA on a $1 \%$ agarose gel (Primer 2). L is $1 \mathrm{kbp}$ marker, M1-F2 contained mature male and female respectively, lane 1-20 contained seedlings 


\section{Discussion}

Primer $1 \& 2$ were male-specific which should bind unto all samples which are male (both mature and assumed male) leaving all female samples (both mature female and assumed female) unbind to distinctively show that those with the same kilo base pairs (kbp) with the marker are males and those which are different in kilo base pairs (kbp) with the markers as females. Primer 3 is a gene neutral (neither male nor female specific) which should bind to all samples. However, the primers used were designed for pawpaw not for nutmeg, although they are all dioecious plants [9]. Parasnis et al., [34] who conducted similar experiment on pawpaw using the same primers had similar results. Sex determination in nutmeg has been worked on in previous experiments by using different primers thus the OPA (Operon) and they yielded good results. A number of polymorphic loci observed were 20 with a total of 160 making the mean number of polymorphic band/ primer. All the primers showed monomorphic loci, the maximum given by OPA 01 primer [22]. However, the primers OPK 01 and OPD 15 which were identified as male specific markers for date palm and rumex respectively $[35,36]$ have given polymorphism for nutmeg with female specificity. The sex determination system in date palm and rumex was XX-XY (XX -female; XY- male) chromosome system [37]. In nutmeg also it appears that sex is genetically determined with a strong possibility of a mono-factorial sex-determining mechanism [38]. Single amplifications show that there is genetic difference between nutmeg and pawpaw. The genetic mechanisms involved in dioecy vary in different plants [39]. Monomorphic loci was identified whiles other studies identified polymorphic loci. Previous experiments in dioecious plants proved that among 100 primers (OPC) evaluated, 75 produced clear DNA profile yielding a total of 971 amplification bands for the bulked sample of male, female and hermaphrodite papaya plants of which 89 bands were polymorphic [39]. This can be attributed to the $\mathrm{MgCl}_{2}$ concentration, temperature and duration for the PCR. According to Sheeja et al. [40] the appropriate concentration of $\mathrm{MgCl} 2$ for effective primer amplification is $2.0 \mathrm{ng}$ but in this experiment, $0.5 \mathrm{ng}$ was used. Moreover, the concentration of DNA samples is a contributing factor to polymorphism or monomorphism.

\section{Conclusion}

Monomorphic loci is common for all nutmeg plants. Hence the inability of farmers to differentiate between a male or female juvenile nutmeg plant when grown on the field. Optimization of PCR parameters will enhance the tendency of achieving polymorphism as identified in other dioecious plants. A further designed nutmeg specific primers could have a better potential of showing unique polymorphism.

\section{Conflict of Interest}

The author declares that there is no conflict of interest.

\section{References}

[1] M. Anandaraj et al., Nutmeg. Extension Pamphlet, II SR, 2005.

[2] United States Department of Agriculture (USDA, 2010). National Genetic Resources Program.

[3] D. Dhingra, A. Sharma, Antidepressant- like activity of n-hexane extract of nutmeg (Myristica fragrans Houtt.) seeds in mice, Journal of Medical Food. 9 (2006) 84-89.

[4] J. Asgarpanah, N. Kazemivash, Phytochemistry and pharmacological properties of Myristica fragrans Houtt.: A review, African Journal of Biotechnology. 11(65) (2012) 12787-12793.

[5] U. Stein, H. Greyer, H. Hentschel, Nutmeg (Myristicin) poisoning- report on fatal case and a series of cases recorded by a poison information centre, Forensic Science International. 118(1) (2001) 87-90. 
[6] K. Jangid, N.D. Jayakumar, S.S. Varghese, Achievable therapeutic effects of Myristica fragrans (Nutmeg) on periodontitis - a short review, International Journal of Pharmacy and Pharmaceutical Sciences. 6(5) (2014) 591-594

[7] B. Yakubov, O. Barazani, A.G. Goldhirish, Combination of SCAR primers and touchdown PCR for sex identification in Pistachia vera L., Scientia Horticulturae. 103 (2005) 473-478.

[8] N. Urazaki et al., A male and hermaphrodite specific RAPD marker for papaya (Carica papaya L.), Theoretical and Applied Genetics. 2 (2002) 281-285.

[9] A.S. Parasnis et al., A highly reliable sex diagnostic PCR assay for mass screening of papaya seedlings, Molecular Breeding. 6 (2000) 337-344.

[10] J.W. Lee et al., Development of an ISSR derived SCAR marker in Korean ginseng cultivar (Panax ginseng C.A. Meyer), Journal of Ginseng Research. 35(1) (2011) 52-59.

[11] P. Manoj, N.S. Banerjee, P. Ravichandran, Development of sex specific molecular markers in dioecious Piper Longum L. plants by differentiated display, Journal of Theoretical and Applied Information Technology. 4(5) (2008) 459-465.

[12] M.S. Vinod et al., Identification of a sex-specific SCAR marker in dioecious Pandanus fascicularis L. (Pandanaceae), Genome. 50 (2007) 834-839.

[13] K.M. Devaiah, P. Venkatasubramanian, Development of SCAR marker for authentication of Pueraria tuberose (Roxb. ex. Willd.) DC, Current Science. 94(10) (2008) 1306-1308.

[14] P. Hernandez, A. Martin, G. Dorado Development of SCARs by direct sequencing of RAPD products: a practical tool for the introgression and marker-assisted selection of wheat, Molecular Breeding. 5(3) (1999) 245-253.

[15] S.S. Renner, R.E. Ricklefs, Dioecy and its correlation in the flowering plants, American Journal of Poot. 82 (1995) 596-606.

[16] C. Ainsworth, Boys and girls come out to play: the molecular biology of dioecious plants, Annals of Botany. 86 (2000) 211-221.

[17] D. Charlesworth, Plant sex determination and sex chromosomes, Heredity. 88 (2002) 94-101.

[18] S. Matsunaga, S. Kawano, Sex determination by sex chromosomes in dioecious plants, Plant Biology. 3 (2001) 481-488.

[19] I. Stehlik, F.R. Blattner, Sex Specific SCAR markers in the dioecious plant Rume nivalis (Polygonacae) and implications for the evolution of sex chromosomes, Theoretical Applied Genetics. 108 (2004) 238-242.

[20] N.C. Oraguize et al., Comparison of RAPD and morpho-nut markers for revealing genetic relationships between Chestnut sp. (Castenea sp.) and New Zealand chestnut selections, New Zealand Journal of Crops Horticultural Science. 26 (1998) 109-115

[21] B. Krishnamoorthy, B. Sasikumar, J. Rema, Genetic variability and segregation of sex in nutmeg (Myristica fragrans Houtt.), Journal of Plantation Crops. 24 (1996) 468-472.

[22] T.E. Sheeja et al., DNA polymorphism in clonal and seedlings progeny of an elite nutmeg (Myristica fragrans Houtt.), Journal of Plantation Crops. 34(2) (2006) 558-561.

[23] N.A. Phadnis, K.G. Choudhary, Sex determination in the seedling stage of nutmeg (Myristica fragrans, Houtt), Tropical Science. 13(4) (1971) 265-274.

[24] B.K. Nayar, R. Rajendra, P. Vatsala, A simple morphological technique distinguish the sex of nutmeg seedlings, Current Science. 46(5) (1976) 156-157. 
[25] E.V. Packiyasothy, E.R. Jansz, H.M. Dharmadasa, Studies on some chemical components of nutmeg (Myristica fragrans Houtt.) leaf directed at determination of sex in seedlings, Journal of the National Science Foundation of Sri Lanka. 19(2) (1991) 91-98.

[26] N. Menzencev et al., Assessment of RAPD markers to detect genetic change in protoplastderived rice plants, Journal of Genetics and Breed. 51 (1997) 97-102.

[27] S. Forapani et al., RAPD markers for potato germplasm characterization, Journal of Genetics and Breed. 53 (1999) 143-147.

[28] S. Kafkas, S. Cetiner, R. Perl-Treves, Development of sex associated RAPD markers in wild Pistacia sp., Journal of Horticultural Science and Biotechnology. 76 (2001) 242-246.

[29] P.S. Virk et al., Use of RAPD for the study of diversity within the Plant Germplasm collections, Heredity. 74 (1995) 170-179.

[30] J.O. Olufowote et al., Comparative evaluation within cultivar variation of rice (Oryzae sativa L.) using microsatellite and RFLP markers, Genome. 40 (1997) 370-378.

[31] E.G.M. Lemos, C.L.S.P. Silva, H.A. Zaidan, Identification of sex in Carica papaya L. using RAPD markers, Euphytica. 127 (2003) 179-184.

[32] K.N. Ganeshaiah et al., Identification of sex sex specific DNA marker in the dioecious tree (nutmeg), Plant Genetic Resource Newsletter. 121 (2000) 59-61.

[33] C. Takrama, CTAB Protocol for Plant DNA extraction, 2000.

[34] A.S. Parasnis et al., A Highly Reliable Sex Diagnostic PCR Assay for mass Screening of Papaya seedlings, Molecular Breeding. 6 (2004) 337-344.

[35] R.A.A.Younis et al., Identification of sex-specific DNA markers for date palm (Phoenix dactylifera L.) using RAPD techniques, Research Journal of Agriculture and Biological Science. 4(4) 2008) 278-284.

[36] K.C. Sink, C. Jiang, RAPD and SCAR markers linked to the sex expression locus M in asparagus, Euphytica. 94(3) (1997) 329-333.

[37] J.S. Parker, Sex chromosomes and sexual differentiation in flowering plants, Chromosomes Today. 10 (1990) 187-198.

[38] M. Flach, Nutmeg cultivar and sex problems, Eng. Summ. Meded. Landb. Hogesh. 66 (1966) 1.

[39] E. Niroshini et al., Detection of SCAR marker linked to sex expression in Carica papaya L., Journal of the National Science Foundation of Sri Lanka. 36(2) (2008) 145-150.

[40] T.E. Sheeja et al., Optimization of DNA isolation and PCR parameters in Myristica sp. and related genera for RAPD and ISSR analysis, Journal of Spices and Aromatic Crops. 17(2) (2008) 91-97. 